\title{
Assessment of the Contributions of Clinician Educators
}

\author{
Karen E. Hauer, $M D^{7}$, and Maxine A. Papadakis, $M D^{1,2}$ \\ 'Department of Medicine, University of California, San Francisco, CA, USA; ${ }^{2}$ San Francisco Veterans Affairs Medical Center, San Francisco, \\ CA, USA.
}

$\mathrm{J}$ Gen Intern Med 25(1):5-6

DOI: $10.1007 / \mathrm{s} 11606-009-1186-3$

(c) Society of General Internal Medicine 2009

$\mathrm{C}$ linician educators play a vital role at medical schools. The number of clinician educators and the scope of their responsibility have grown at academic medical centers over the last two decades ${ }^{1}$. Clinician educators provide expert patient care that has become critical to the financial viability of medical centers. Clinician educators also teach and supervise medical students and residents in the inpatient and, increasingly, in the ambulatory setting ${ }^{2}$.

Despite clinical expertise and enthusiasm and skill for teaching, clinician educators face many challenges in sustaining and growing their academic careers. They experience varying and often unclear criteria by which their qualifications for promotion are judged. Clinical departments lack consistent measures to assess expertise in clinical care and teaching, and frequently default to evaluating clinician educators using criteria designed for researchers ${ }^{2}$. However, clinician educators typically shoulder large clinical commitments that make it difficult or impossible for them to produce scholarship at a level comparable to those with substantial protected time for research. Clinician educators' teaching contributions, while large in scope, may be evaluated using narrowly focused tools. These obstacles suggest that clinician educators require different mechanisms to evaluate their productivity that are better aimed at capturing the range of their performance.

In this issue of the Journal of General Internal Medicine, Beckman and colleagues present results from a longitudinal study of resident physicians' psychological characteristics and their evaluations of their faculty physician's teaching quality ${ }^{3}$. The authors hypothesized that resident physicians' well-being and empathy would be positively associated with their assessments of their faculty teachers. The subjects were residents in the Mayo Clinic internal medicine residency program enrolled in a broader study of resident well-being. Using four different standardized surveys, the authors gained information about residents' quality of life, burnout, empathy, and depression throughout their training. This information was correlated with the same residents' ratings of their faculty physician teachers, using a 16-item Likert-scale form. Overall, 1191 monthly assessments of 356 faculty by 209 residents over 13 months were compiled; in addition, resident ratings of the same faculty from the prior year were included in the model. The strongest item association with faculty teaching ratings was the prior year's ratings of the same faculty. Residents'

Published online December 17, 2009 empathy was also modestly associated with their ratings of their faculty attendings' teaching, whereas the other psychological characteristics of the residents were not.

The authors are to be commended for their careful, longitudinal study design. Such longitudinal databases with rigorous follow-up of subjects are uncommon in medical education research. Other notable examples of longitudinal medication education research include products from the Jefferson Medical College and the Medical Schools Outcomes Database (MSOD) collaborative in Australia ${ }^{4,5}$. In contrast to the more prevalent cross-sectional study design, longitudinal cohorts allow educators to characterize professional development and the effects of training experiences over time.

The study by Beckman also provides important insights into the role of trainees' personal characteristics and well-being in their perceptions of their teachers. Trainees' empathy is critical to their ability to provide compassionate care to patients and to function as professional, collaborative team members in patient care settings. Whereas the authors suggest that empathy is a relatively stable innate characteristic, we are more optimistic that empathy can grow if it is carefully nurtured. For instance, studies have shown that levels of empathy decline during internship, indicating that empathy is influenced by one's experiences ${ }^{6}$. However, empathy can also be approached as a cognitive trait that can be developed in learners through thoughtful, intentional training $^{7}$. Clinician educators are key in enhancing trainees' experience developing empathy. Trainees with role models more like themselves may find their interactions with those faculty members more positive and feel that those supervisors understand and empathize with their perspective more completely $^{8}$. These learners receive guidance and support from these role models that enhance their own skills and careers.

We must also consider important questions about the role of teaching evaluations of faculty physicians as a measure of their success as teachers. Is it really reassuring to faculty that ratings of their teaching are stable year to year? For the most part, we believe that the findings by Beckman are indeed reassuring ${ }^{3}$. Although a successful clinician educator will occasionally face a difficult student, an outlier who can potentially bring down the teacher's ratings, these students are rare and their challenges can be addressed individually. However, for those clinician educators whose ratings on teaching evaluations consistently fall below expectations, mediocre or poor evaluations can be frustrating and belie the effort devoted to teaching. The use of a single method of measuring the impact of teaching leads to a capricious process that shortchanges clinician educators. Other assessment strategies that capture teaching volume, awards, innovations, and teaching quality can more holistically present the contributions of medical teachers with greater validity ${ }^{9,10}$. Methods of quantifying educational contributions and aligning 
those contributions with financial incentives further reward the work of clinician educators ${ }^{11,12}$.

To support the career trajectories of clinician educators, Fleming and colleagues argue for the creation of a separate and equitable promotion track. This track would have appropriate yardsticks to measure the productivity of clinician educators, rather than applying a lesser version of the traditional criteria that are used for promotion within the clinician researcher track ${ }^{13}$. What are some appropriate expectations for promotion in the clinician educator track? Certainly, resident teaching evaluations should not be the only measure of a clinician educators' performance, and the article by Beckman echoes the sentiment that they are but one, imperfect measure ${ }^{3}$. Submitting abstracts and developing workshops for regional and national meetings are bona fide scholarly activities and should be recognized as such. Many clinician educators influence trainees' specialty choices and decisions to pursue academic careers through role modeling ${ }^{14}$; such mentoring should be tracked and showcased in promotions materials. Educational administration and service constitute another category of productivity. Many of these contributions could be presented in an educator's portfolio, which can better showcase these activities than traditional curriculum vitae ${ }^{15}$.

More broadly, the examination of evaluations of clinician educators challenges us to consider the factors that lead these faculty members to thrive or meet failure in their academic careers. Clinician educators face several obstacles in the academic environment. Most assuredly, they are not immune to burnout, which may be more prevalent than ever as an unintended consequence of the pervasive attention that is now paid to limiting resident duty hours. It is the clinician educators who have the clinical expertise and availability to assume extra clinical duties so that residents can adhere to duty hour protocols. Unfortunately, clinician educators themselves are not protected by duty hour policies or patient caps. They are at risk for slower trajectories to promotion despite their intensive duty hours because more intensive clinical activities do not translate into activities more highly regarded by promotion committees ${ }^{16}$.

How can we nurture clinician educators to achieve and maintain their passion for clinical care and education in the academic medical center environment? Clinician educators need an academic home within their own institutions that will support them and unify a critical mass of colleagues devoted to the same goals. Clinician educators often embark on their careers straight out of residency without specialized training to become educators or scholars. Faculty development, mentoring and role modeling are crucial to avoid burnout and position clinician educators to succeed in the promotions process. Those faculty focused on education deserve a forum to share academic work. An increasing number of medical schools provide such structure through teaching academies ${ }^{17}$.

We conclude with recommendations for academic departments to advance the mission of clinician educators, and for medical education researchers to advance the quality of medical education research. Beckman's study prompts us to encourage further high-quality research in medical education that incorporates longitudinal data collection. We would also emphasize the value of collaboration across institutions and via national organizations. Educational program evaluation, and evaluation of clinical teachers, must incorporate multiple assessment strategies, not just end-of-month teaching evaluations, to capture the range of performance of both teachers and learners with evidence of validity. And finally, clinician educators must be given the opportunity to have their work assessed by criteria that do justice to their essential contributions to the clinical and teaching missions of academic centers.

Corresponding Author: Karen E. Hauer, MD; Department of Medicine, University of California, 533 Parnassus Ave, U113A, Box 0131, San Francisco, CA 94143-0131, USA (e-mail: Karen. hauer@ucsf.edu).

\section{REFERENCES}

1. Osborn LM, Sostok M, Castellano PZ, Blount W, Branch WT Jr. Recruiting and retaining clinician-educators. Lessons learned from three programs. J Gen Intern Med. 1997;12(Suppl 2):S83-9.

2. Levinson W, Rubenstein A. Integrating clinician-educators into academic medical centers: challenges and potential solutions. Acad Med. 2000;75:906-12.

3. Beckman TJ, Reed DA, Shanafelt TD, West CP. Impact of resident wellbeing and empathy on assessments of faculty physicians. J Gen Intern Med. XXXXX

4. (www.medicaldeans.org.au/msod.html) Accessed October 12, 2009.

5. Hojat M, Paskin DL, Callahan CA, Nasca TJ, Louis DZ, Veloski J, Erdmann JB, Gonnella JS. Components of postgraduate competence: analyses of thirty years of longitudinal data. Med Educ. 2007;41:982-9.

6. Bellini LM, Baime M, Shea JA. Variation of mood and empathy during internship. JAMA. 2002;287:3143-6.

7. Crandall SJ, Marion SG. Identifying attitudes towards empathy: an essential feature of professionalism. Acad Med. 2009;84:1174-6.

8. Wright SM, Carrese JA. Serving as a physician role model for a diverse population of medical learners. Acad Med. 003;78:623-8.

9. Atasoylu A, Wright SM, Beasley BW, Cofrancesco J, Macpherson DS, Partridget T, Thomas PA, Bass EB. Promotion criteria for clinicianeducators. J Gen Intern Med. 2003;18:711-6.

10. Newman LR, Lown BA, Jones RN, Johansson A, Schwartzstein RM. Developing a peer assessment of lecturing instrument: lessons learned. Acad Med. 2009;84(8):1104-10.

11. Schindler N, Winchester DP, Sherman H. Recognizing clinical faculty's contributions in education. Acad Med. 2002;77(9):940-1. Review.

12. Stites S, Vansaghi L, Pingleton S, Cox G, Paolo A. Aligning compensation with education: design and implementation of the Educational Value Unit (EVU) system in an academic internal medicine department. Acad Med. 2005;80(12):1100-6.

13. Fleming VM, Schindler N, Martin GJ, DaRosa DA. Separate and equitable promotion tracks for clinician-educators. JAMA. 2005;294:1101-4.

14. Wright SM, Kern DE, Kolodner K, Howard DM, Brancati FL. Attributes of excellent attending-physician role models. New Engl J Med. 1998;339: 1986-93.

15. Simpson D, Fincher RM, Hafler JP, Irby DM, Richards BF, Rosenfeld GC, Viggiano TR. Advancing educators and education by defining the components and evidence associated with educational scholarship. Med Educ. 2007;41:1002-9.

16. Thomas PA, Diener-West M, Canto MI, Martin DR, Post WS, Streiff MB. Results of an academic promotion and career path survey of faculty at the Johns Hopkins University School of Medicine. Acad Med. 2004;79:258-64.

17. Irby DM, Cooke M, Lowenstein D, Richards B. The academy movement: a structural approach to reinvigorating the educational mission. Acad Med. 2004;79:729-36. 